\title{
Determination of Mark-Houwink-Sakurada Constants for Mea- surements of the Molecular Weights by Gel Permeation Chromatography I. On the Generalization of Mathematical Procedure
}

\author{
Katsukiyo ITO and Takamitsu UKAI* \\ Government Industrial Research Institute, \\ Nagoya Kita-ku, Nagoya 462, Japan
}

(Received January 20, 1986)

\begin{abstract}
Fourteen equations in terms of molecular weights and intrinsic viscosity are shown to determine Mark-Houwink-Sakurada (MHS) constants on the basis of gel permeation chromatography (GPC), six equations being for determination from one sample, four from two samples, and four by the method of least squares. These equations are examined, using the data obtained for poly(methyl methacrylate). It is pointed out that the determination of MHS constants from one sample is very sensitive to the measured condition of GPC, and thus we should get good GPC data. Using two samples, the reasonable MHS constants are obtained when the weight- and viscosity-average molecular weights are known. Using more than two samples, the MHS constants are determined by the method of least squares. It is shown that the MHS equation obtained previously under a given condition is transferred to a MHS equation under another condition by GPC where the viscosity-average molecular weights calculated by the former equation are used. Further, using the GPC data obtained under good conditions, good MHS constants can be determined when the number- and weight-average molecular weights are known.

KEY WORDS Molecular Weights / Intrinsic Viscosity / Mark-Houwink-

Sakurada Constants / Gel Permeation Chromatography / Calibration Curve /

Polystyrene / Poly(methyl methacrylate) / Method of Least Squares /
\end{abstract}

In polymer science, measurement of the molecular weight of a polymer is very important. It has been carried out by the osmotic method, the light scattering method, gel permeation chromatography (GPC), etc. Recently, GPC is the most popular method. To calculate the molecular weights by GPC, we have to make a calibration curve using several standard polymer samples whose molecular weight distributions are narrow. However, their preparations are difficult except for several kinds of polymers such as polystyrene, ethylene oxide, etc. Therefore, many workers have proposed modifications of a calibration curve made by the standard polymer to apply it to other polymers. Almost all the modifications are based on the suggestion $^{1}$ that the hydrodynamic volume of polymer can be used to establish a universal calibration curve in GPC, because all polymers have the same hydrodynamic volume at a given elution volume on the assumption that $\Phi$ in the Flory-Fox equation is invariable. ${ }^{2}$ That is, the modifications are based on an equation:

$$
[\eta]_{\mathrm{s}} M_{\mathrm{s}}=[\eta] M
$$

Using the Mark-Houwink-Sakurada (MHS) equation:

* On leave from Aichi Institute of Technology, Toyota-shi, Japan. 


$$
[\eta]=K M^{\mathrm{a}}
$$

Equation 1 is written as:

$$
K_{\mathrm{s}} M_{\mathrm{s}}^{1+a_{\mathrm{s}}}=K M^{1+a}
$$

The modification of the calibration curve has been carried out by eq 3 . Thus, we have to determine $a$ and $K$ as MHS constants. In the past, the MHS constants have been determined when the number- and weight-average molecular weights and the intrinsic viscosities of one sample or two samples were known. ${ }^{3-8}$ However, the viscosity-average molecular weights have not been used. Probably, using a MHS equation obtaind previously when the molecular weight distribution was narrow, we may calculate the precise viscosity-average molecular weights. Then, the MHS constants $\left(a_{v}, K_{v}\right)$ in such an equation under the previous condition may be transferred to new MHS constants $(a, K)$ under the other condition. On the above, using eq 3 , we can make ten more methods in terms of the number-, weight-, and/or viscosity-average molecular weights and/or the intrinsic viscosities, three methods being determinations from one sample, three from two samples, and four from by the method of least squares. That is, we have fourteen methods to determine the MHS constants by GPC. However, on comparison of all fourteen methods, the applicability has not been examined. Therefore, the aim of this article is to examine such applicability. Then, all fourteen methods are presented. Every method is examined, using the data obtained for poly(methyl methacrylate) (PMMA).

\section{THEORY}

The number-, weight-, and viscosity-average molecular weights and the intrinsic viscosity of a polydisperse polymer are given by:

$$
\begin{aligned}
& M_{n}=\sum_{i=1}^{\infty} N_{i} M_{i} / \sum N_{i} \\
& M_{w}=\sum N_{i} M_{i}^{2} / \sum N_{i} M_{i} \\
& M_{v}=\left(\sum N_{i} M_{i}^{1+a_{\mathrm{v}}} / \sum N_{i} M_{i}\right)^{1 / a_{\mathrm{v}}} \\
& {[\eta]=K\left(\sum N_{i} M_{i}^{1+a_{\mathrm{v}}} / \sum N_{i} M_{i}\right)^{a / a_{\mathrm{v}}}}
\end{aligned}
$$

Using eq 3 , the molecular weight of $i$-th species in a polymer is given by:

$$
M_{i}=\left[\left(K_{\mathrm{s}} / K\right)^{1 /(1+a)}\right]\left[M_{i \mathrm{~s}}^{\left(1+a_{\mathrm{s}}\right) /(1+a)}\right]
$$

The weight fraction of $i$-th species is given by:

$$
w_{i}=N_{i} M_{i} / \sum N_{i} M_{i}
$$

Using eq 8 and 9, eq $4-6$ and eq 7.become:

$$
\begin{aligned}
& M_{n}=\left[\left(K_{\mathrm{s}} / K\right)^{1 /(1+a)}\right] /\left[\sum w_{i} / M_{i \mathrm{~s}}^{\left(1+a_{\mathrm{s}}\right) /(1+a)}\right] \\
& M_{w}=\left[\left(K_{\mathrm{s}} / K\right)^{1 /(1+a)}\right]\left[\sum w_{i} M_{i \mathrm{~s}}^{\left(1+a_{\mathrm{s}}\right) /(1+a)}\right] \\
& M_{v}=\left[\left(K_{\mathrm{s}} / K\right)^{1 /(1+a)}\right]\left[\sum w_{i} M_{i \mathrm{~s}}^{a_{\mathrm{v}}\left(1+a_{\mathrm{s}}\right) /(1+a)}\right]^{1 / a_{\mathrm{v}}} \\
& {[\eta]=\left[K_{\mathrm{s}}^{a /(1+a)} K^{1 /(1+a)}\right]\left[\sum w_{i} M_{i \mathrm{~s}}^{a\left(1+a_{\mathrm{s}}\right) /(1+a)}\right]}
\end{aligned}
$$

Here, the $K$-value is calculated by:

$$
\begin{aligned}
& K=K_{\mathrm{s}}\left[\sum w_{i} / M_{i \mathrm{~s}}^{\left(1+a_{\mathrm{s}}\right) /(1+a)} / M_{n}\right]^{(1+a)} \\
& K=K_{\mathrm{s}}\left[\sum w_{i} M_{i \mathrm{~s}}^{\left(1+a_{\mathrm{s}}\right) /(1+a)} / M_{w}\right]^{(1+a)} \\
& K=K_{\mathrm{s}}\left[\left(\sum w_{i} M_{i \mathrm{~s}}^{\left(1+a_{\mathrm{s}}\right) /(1+a)}\right)^{1 / a_{\mathrm{v}}} / M_{v}\right]^{(1+a)} \\
& K=[\eta] / K_{\mathrm{s}}^{a}\left[\sum w_{i} M_{i \mathrm{~s}}^{a\left(1+a_{\mathrm{s}}\right) /(1+a)}\right]^{(1+a)}
\end{aligned}
$$

\section{Determination of a from One Sample}

When $M_{n}, M_{w}$, and [ $\left.\eta\right]$ are known, the following three equations can be obtained from eq 10 and 11 , eq 10 and 13 , and eq 11 and 13 , to determine $a .^{3-7}$

$$
\begin{aligned}
& M_{w} / M_{n}=\left[\sum w_{i} M_{i \mathrm{~s}}^{a\left(1+a_{\mathrm{s}}\right) /(1+a)}\right]\left[\sum w_{i} / M_{i \mathrm{~s}}^{\left(1+a_{\mathrm{s}}\right) /(1+a)}\right] \\
& {[\eta] M_{n} / K_{\mathrm{s}}=\left[\sum w_{i} M_{i \mathrm{~s}}^{a\left(1+a_{\mathrm{s}}\right) /(1+a)}\right] /\left[\sum w_{i} / M_{i \mathrm{~s}}^{\left(1+a_{\mathrm{s}}\right) /(1+a)}\right]} \\
& {[\eta] M_{w} / K_{\mathrm{s}}=\left[\sum w_{i} M_{i \mathrm{~s}}^{a\left(1+a_{\mathrm{s}}\right) /(1+a)}\right]\left[\sum w_{i} M_{i \mathrm{~s}}^{\left(1+a_{\mathrm{s}}\right) /(1+a)}\right]}
\end{aligned}
$$

Further, in orde1 to determine a, we can make the follwing three equations, combining two of eq $10-13$. 


$$
\begin{aligned}
& {[\eta] M_{v} / K_{\mathrm{s}}=\left[\sum w_{i} M_{i \mathrm{~s}}^{a\left(1+a_{\mathrm{s}}\right) /(1+a)}\right]\left[\sum w_{i} M_{i \mathrm{~s}}^{a_{\mathrm{v}}\left(1+a_{\mathrm{v}}\right) /(1+a)}\right]^{1 / a_{\mathrm{v}}}} \\
& M_{v} / M_{n}=\left[\sum w_{i} M_{i \mathrm{~s}}^{a_{\mathrm{v}}\left(1+a_{\mathrm{s}}\right) /(1+a)}\right]^{1 / a_{\mathrm{v}}}\left[\sum w_{i} / M_{i \mathrm{~s}}^{\left(1+a_{\mathrm{s}}\right) /(1+a)}\right] \\
& M_{w} / M_{v}=\left[\sum w_{i} M_{i \mathrm{~s}}^{\left(1+a_{\mathrm{s}}\right) /(1+a)}\right] /\left[\sum w_{i} M_{i \mathrm{~s}}^{a_{\mathrm{v}}\left(1+a_{\mathrm{s}}\right) /(1+a)}\right]^{1 / a_{\mathrm{v}}}
\end{aligned}
$$

After determining the $a$-value, the $K$-value can be calculated from eq $14-17$.

\section{Determination of a from Two Samples}

When the intrinsic viscosities of two samples are known, the $a$-value can be calculated by: $: 3,7$

$$
[\eta]_{1} /[\eta]_{2}=\left[\sum w_{i 1} N_{i \mathrm{~s}}^{a\left(1+a_{\mathrm{s}}\right) /(1+a)}\right] /\left[\sum w_{i 2} M_{i \mathrm{~s}}^{a\left(1+a_{\mathrm{s}}\right) /(1+a)}\right]
$$

Further, to determine $a$, the following three equations are obtained from eq $10-12$.

$$
\begin{aligned}
& M_{n 1} / M_{n 2}=\left[\sum w_{i 2} / M_{i \mathrm{~s}}^{\left(1+a_{\mathrm{s}}\right) /(1+a)}\right] /\left[\sum w_{i 1} / M_{i \mathrm{~s}}^{\left(1+a_{\mathrm{s}}\right) /(1+a)}\right] \\
& M_{w 1} / M_{w 2}=\left[\left(\sum w_{i 1} M_{i \mathrm{~s}}^{\left(1+a_{\mathrm{s}}\right) /(1+a)}\right) /\left(\sum w_{i 2} M_{i \mathrm{~s}}^{\left(1+a_{\mathrm{s}}\right) /(1+a)}\right)\right] \\
& M_{v 1} / M_{v 2}=\left[\left(\sum w_{i 1} M_{i \mathrm{~s}}^{a_{\mathrm{v}}\left(1+a_{\mathrm{s}}\right) /(1+a)}\right) /\left(\sum w_{i 2} M_{i \mathrm{~s}}^{a_{\mathrm{v}}\left(1+a_{\mathrm{s}}\right) /(1+a)}\right)\right]^{1 / a_{\mathrm{v}}}
\end{aligned}
$$

The $K$-value can be calculated from eq 14 17.

Determination of $a$ and $K$ by the Method of

\section{Least Squares}

When we have more samples than two, we can use the method of least squares. ${ }^{9}$ In the present case, $F_{j}$ is set as the difference between the value measured for $M_{n}, M_{w}, M_{v}$, or [ $\left.\eta\right]$ and the respective value calculated using $a_{j}$ and $K_{j}$ at $j$-th computations. Then, $F_{j}$ is given by:

$$
F_{j}=(\partial f / \partial K) \mathrm{d} K_{j+1}+(\partial f / \partial a) \mathrm{d} a_{j+1}+d_{j}
$$

where $f$ denotes one function of eq $10-13$. The values of $\mathrm{d} K_{j+1}\left(=K_{j+1}-K_{j}\right)$ and $\mathrm{d} a_{j+1}$ $\left(=a_{j+1}-a_{j}\right)$ can be calculated under the condition that $\sum_{n=1}^{m}\left(d_{j}\right)_{n}^{2}$ is minimized. Thus, we show the pair of respective partial differential equations as $\partial f / \partial K$ and $\partial f / \partial a$ in the following.

When the number-average molecular weights are known, the pair is given by:

$$
\begin{aligned}
\partial M_{n} / \partial K= & -\left[\left(K_{\mathrm{s}} / K\right)^{1 /(1+a)}\right] /\left[(1+a) K \sum w_{i} / M_{i \mathrm{~s}}^{\left(1+a_{\mathrm{s}}\right) /(1+a)}\right] \\
\partial M_{n} / \partial a= & -\left\{\left[\left(K_{\mathrm{s}} / K\right)^{1 /(1+a)}\right] /\left[(1+a)^{2} \sum w_{i} / M_{i \mathrm{~s}}^{\left(1+a_{\mathrm{s}}\right) /(1+a)}\right]^{2}\right\}\left\{\left[\ln \left(K_{\mathrm{s}} / K\right)\right]\left[\sum w_{i} / M_{i \mathrm{~s}}^{\left(1+a_{\mathrm{s}}\right) /(1+a)}\right]\right. \\
& \left.+\left(1+a_{\mathrm{s}}\right)\left[\sum w_{i}\left(\ln M_{i \mathrm{~s}}\right) / M_{i \mathrm{~s}}^{\left(1+a_{\mathrm{s}}\right) /(1+a)}\right]\right\}
\end{aligned}
$$

When the weight-average molecular weights are known, the pair is:

$$
\begin{aligned}
\partial M_{w} / \partial K= & -\left[\left(K_{\mathrm{s}} / K\right)^{1 /(1+a)}\right]\left[\sum w_{i} M_{i \mathrm{~s}}^{\left(1+a_{\mathrm{s}}\right) /(1+a)}\right] /[K(1+a)] \\
\partial M_{w} / \partial a= & -\left[\left(K_{\mathrm{s}} / K\right)^{1 /(1+a)} /(1+a)^{2}\right]\left\{\left[\ln \left(K_{\mathrm{s}} / K\right)\right]\left[\sum_{w i} M_{i}^{\left(1+a_{\mathrm{s}}\right) /(1+a)}\right]\right. \\
& \left.+\left(1+a_{\mathrm{s}}\right)\left[\sum\left(\ln M_{i \mathrm{~s}}\right) w_{i} M_{i \mathrm{~s}}^{\left(1+a_{\mathrm{s}}\right) /(1+a)}\right]\right\}
\end{aligned}
$$

When the viscosity-average molecular weights are known, we use: 


$$
\begin{aligned}
\partial M_{v} / \partial K= & {\left[\left(K_{\mathrm{s}} / K\right)^{1 /(1+a)}\right]\left[\sum w_{i} M_{i \mathrm{~s}}^{a_{\mathrm{v}}\left(1+a_{\mathrm{s}}\right) /(1+a)}\right]^{1 / a_{\mathrm{v}}} } \\
\partial M_{v} / \partial a= & {\left[\left(K_{\mathrm{s}} / K\right)^{1 /(1+a)}\right]\left[\sum w_{i} M_{i \mathrm{~s}}^{a_{\mathrm{v}}\left(1+a_{\mathrm{s}}\right) /(1+a)}\right]^{1 / a_{\mathrm{v}}}\left\{\ln \left(K_{\mathrm{s}} / K\right)\right.} \\
& \left.+\left(1+a_{\mathrm{s}}\right)\left[\sum\left(\ln M_{i \mathrm{~s}}\right) w_{i} M_{i \mathrm{~s}}^{a_{\mathrm{v}}\left(1+a_{\mathrm{s}}\right) /(1+a)}\right] /\left[\sum w_{i} M_{i \mathrm{~s}}^{a_{\mathrm{v}}\left(1+a_{\mathrm{s}}\right) /(1+a)}\right]\right\}
\end{aligned}
$$

When the intrinsic-viscosities are known, the pair is:

$$
\begin{aligned}
\partial[\eta] / \partial K= & -\left[\left(K_{\mathrm{s}} / K\right)^{a /(1+a)}\right]\left[\sum w_{i} M_{i \mathrm{~s}}^{a\left(1+a_{\mathrm{s}}\right) /(1+a)}\right] \\
\partial[\eta] / \partial a= & {\left[K_{\mathrm{s}}^{a /(1+a)} K^{1 /(1+a)} /(1+a)^{2}\right]\left\{\left[\ln \left(K_{\mathrm{s}} / K\right)\right]\left[\sum w_{i} M_{i \mathrm{~s}}^{a\left(1+a_{\mathrm{s}}\right) /(1+a)}\right]\right.} \\
& \left.+\left(1+a_{\mathrm{s}}\right)\left[\sum\left(\ln M_{i \mathrm{~s}}\right) w_{i} M_{i \mathrm{~s}}^{a\left(1+a_{\mathrm{s}}\right) /(1+a)}\right]\right\}
\end{aligned}
$$

Using the pair of differential equations, we obtain the numerical values of $\mathrm{d} K_{j+1}$ and $\mathrm{d} a_{j+1}$, then more probable values than $K_{j}$ and $a_{j}$ are calculated to be $K_{j+1}=K_{j}+\mathrm{d} K_{j+1}$ and $a_{j+1}=a_{j}+\mathrm{d} a_{j+1}$. Here, the values of $K_{j+1}$ and $a_{j+1}$, obtained when $\left|K_{j+1} / K_{j}-1\right|<$ 0.005 and $\left|a_{j+1} / a_{j}-1\right|<0.005$, are presented as the most probable MHS constants.

\begin{tabular}{|c|c|c|c|}
\hline \multicolumn{2}{|c|}{ Equations } & \multirow{2}{*}{$\frac{\text { Number of samples }}{m}$} & \multirow{2}{*}{$\mathrm{MW}^{\mathrm{a}}$ and/or $[\eta]$} \\
\hline$a$ & $K$ & & \\
\hline 18 & 14,15 & 1 & $M_{n}, M_{w}$ \\
\hline 19 & 14,17 & 1 & $M_{n},[\eta]$ \\
\hline 20 & 15,17 & 1 & $M_{w},[\eta]$ \\
\hline 21 & 16,17 & 1 & $M_{v},[\eta]$ \\
\hline 22 & 14,16 & 1 & $M_{n}, M_{v}$ \\
\hline 23 & 15,16 & 1 & $M_{w}, M_{v}$ \\
\hline 24 & 17 & 2 & {$[\eta]$} \\
\hline 25 & 14 & 2 & $M_{n}$ \\
\hline 26 & 15 & 2 & $M_{w}$ \\
\hline 27 & 16 & 2 & $M_{v}$ \\
\hline \multicolumn{2}{|c|}{$29 a, b$} & $m \geq 3$ & $M_{n}$ \\
\hline \multicolumn{2}{|c|}{$30 a, b$} & $m \geq 3$ & $M_{w}^{n}$ \\
\hline \multicolumn{2}{|c|}{$31 \mathrm{a}, \mathrm{b}$} & $m \geq 3$ & $M_{v}^{w}$ \\
\hline \multicolumn{2}{|c|}{$32 a, b$} & $m \geq 3$ & {$[\eta]$} \\
\hline
\end{tabular}

The number of samples and the molecular weights and/or the intrinsic viscosities, which are necessary to use the above equations, are shown in Table I.

Table I. Equations to determine MHS constants

a MW, molecular weight.

\section{EXPERIMENTAL}

Two standard calibration curves were made between elution volume (count number) and the molecular weight of polystyrene purchased from Toyo Soda Ltd Company and General Science Corporation ( $M=$ 800 to $2.06 \times 10^{7}$ ) (Table II and Figure 1). To supplement these curves, commercial ethylbenzene $(M=106)$ and diphenylpropane (196) were used. A Toyo Soda GPC HLC802A with TSK gel GMH as columns was used at $25 \pm 1^{\circ} \mathrm{C}$ and $38 \pm 1^{\circ} \mathrm{C}$, where tetrahydrofuran (THF) was used as the solvent.

The samples of PMMA, whose number- and weight-average molecular weights are known, were purchased from General Science Corporation. Using these, determinations of MHS constants from one sample and two samples were carried out. For determination by the method of least squares, PMMA was formed by radical polymerization. Its weight-average molecular weight was measured by the light scattering method, using a Toyo Soda LS8 and GPC HLC$802 \mathrm{~A}$. The number-average molecular weight was calculated, using a calibration curve for PMMA modified by the MHS equation obtained previously at $25 \pm 1^{\circ} \mathrm{C}$ in $\mathrm{THF} .{ }^{10}$ Intrinsic viscosities were measured at $25.0 \pm 0.05^{\circ} \mathrm{C}$ in THF and acetone and at $38.0 \pm 0.05^{\circ} \mathrm{C}$ in THF. The molecular weights and intrinsic viscosities of the above PMMA are shown in Table III. The viscosity-average molecular weights were calculated using the MHS equa- 
Table II. The elution volume at given molecular weight of standard polystyrene when elution volume rate is $1 \mathrm{ml} \mathrm{min}^{-1}$

\begin{tabular}{rrr}
\multicolumn{1}{c}{$M$} & \multicolumn{2}{c}{$v$} \\
\cline { 2 - 3 } & $25^{\circ} \mathrm{C}$ & $38^{\circ} \mathrm{C}$ \\
\hline $106^{\mathrm{a}}$ & 40.0 & 42.2 \\
$196^{\mathrm{b}}$ & 39.1 & 41.2 \\
800 & 36.9 & 38.8 \\
2200 & 35.4 & 37.2 \\
4000 & 34.8 & 36.5 \\
17500 & 32.5 & 34.0 \\
50000 & 30.5 & 32.2 \\
233000 & 27.2 & 28.6 \\
422000 & 26.2 & 27.3 \\
600000 & 25.2 & 26.3 \\
1800000 & 23.3 & 24.5 \\
4480000 & 23.0 & 23.6 \\
8420000 & 22.8 & 23.2 \\
20600000 & 22.6 & 22.7
\end{tabular}

a Ethylbenzene.

b Diphenylpropane.

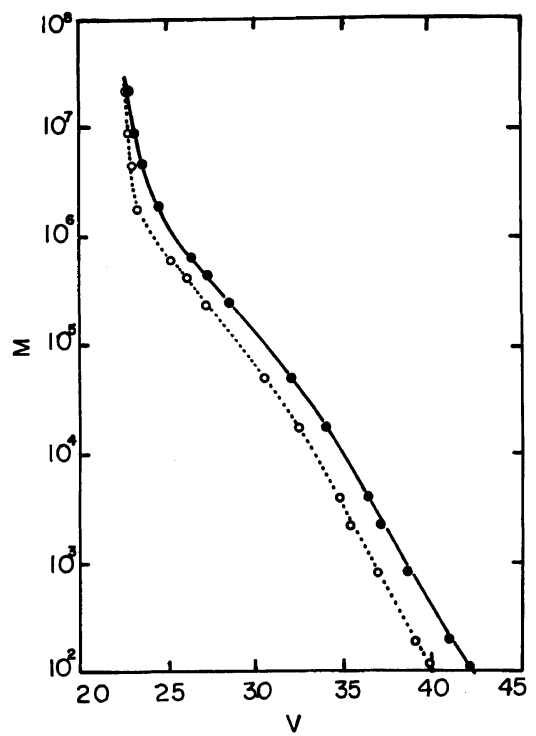

Figure 1. The calibration curves for polystyrene at $25^{\circ} \mathrm{C}(\bigcirc)$ and $38^{\circ} \mathrm{C}(\bigcirc)$.

tions with $\left(a_{\mathrm{v}}, K_{\mathrm{v}}\right)$ obtained when the samples of the molecular weight distribution being narrow were used. ${ }^{11-14}$
Table III. The molecular weights and intrinsic viscosities of PMMA to determine MHS constants

\begin{tabular}{cccccc}
\hline & & \multicolumn{2}{c}{$[\eta]_{\mathrm{THF}}$} & & {$[\eta]_{\text {acetone }}$} \\
\cline { 3 - 4 } \cline { 3 - 4 }$M_{n}$ & $M_{w}$ & $25^{\circ} \mathrm{C}$ & $38^{\circ} \mathrm{C}$ & & $25^{\circ} \mathrm{C}$ \\
\hline $13700^{\mathrm{c}}$ & $33300^{\mathrm{c}}$ & 0.160 & 0.162 & & 0.125 \\
$46400^{\mathrm{c}}$ & $93300^{\mathrm{c}}$ & 0.320 & 0.330 & & 0.235 \\
$119200^{\mathrm{c}}$ & $490200^{\mathrm{c}}$ & 1.030 & 1.025 & & 0.675 \\
$113200^{\mathrm{a}, \mathrm{d}}$ & $175600^{\mathrm{b}, \mathrm{d}}$ & 0.520 & 0.530 & & 0.360 \\
$126500^{\mathrm{a}, \mathrm{d}}$ & $218800^{\mathrm{b}, \mathrm{d}}$ & 0.610 & 0.624 & & 0.420 \\
\hline
\end{tabular}

a Calculated by GPC.

b Measured by the light scattering method.

c Purchased from General Science Corporation.

d Formed by radical polymerization.

\section{RESULTS AND DISCUSSION}

A MHS equation for polystyrene in THF is: ${ }^{15}$

$$
[\eta]=1.60 \times 10^{-4} M^{0.706} \text { at } 25^{\circ} \mathrm{C}
$$

At $38^{\circ} \mathrm{C}$, eq 34 is obtained as:

$$
[\eta]=1.247 \times 10^{-4} M^{0.720} \text { at } 38^{\circ} \mathrm{C}
$$

As shown in Figure 1, the calibration curve at $38^{\circ} \mathrm{C}$ is better than that at $25^{\circ} \mathrm{C}$, because the former can be used over a wider range of the elution volume or count number and, especially, when $v \leq 24, \mathrm{~d} M / \mathrm{d} v$ at $38^{\circ} \mathrm{C}$ is not steeper than that at $25^{\circ} \mathrm{C}$. The MHS constants for PMMA at $38^{\circ} \mathrm{C}$ may be nearly equal to those at $25^{\circ} \mathrm{C}$, because $[\eta]_{38}$ is approximated to $[\eta]_{25}$ as shown in Table III.

\section{Determination of $a$ and $K$ from One Sample}

Estimation of the $a$-value was tried using eq $18-23$, the $K$-value calculated if the $a$-value was obtained. The $a$-value at $25^{\circ} \mathrm{C}$, which is in $1 / 2$ to $1,{ }^{2}$ could not be obtained from $[\eta] M_{n} / K_{\mathrm{s}},[\eta] M_{w} / K_{\mathrm{s}},[\eta] M_{v} / K_{\mathrm{s}}$, and $M_{w} / M_{v}$, except $M_{w} / M_{n}$ and $M_{v} / M_{n}$ (Table IV). The determination by $M_{w} / M_{n}$ may be better than that by $M_{v} / M_{n}$, because the MHS constants were obtained from all three samples by the former, but they were obtained from only two by the later. Generally, $a$ increases and $K$ de- 


\section{K. ITO and T. UKAI}

Table IV. The values of MHS constants obtained from one sample

\begin{tabular}{|c|c|c|c|c|c|c|c|c|c|}
\hline \multirow{2}{*}{$M_{n}$} & \multirow{2}{*}{$M_{w}$} & \multicolumn{2}{|c|}{$M_{w} / M_{n}^{\mathrm{b}}$} & \multicolumn{2}{|c|}{$M_{v} / M_{n}^{\mathrm{b}}$} & \multicolumn{2}{|c|}{$[\eta] M_{n}^{\mathrm{c}}$} & \multicolumn{2}{|c|}{$[\eta] M_{w}{ }^{c}$} \\
\hline & & $a$ & $10^{4} \mathrm{~K}$ & $a$ & $10^{4} \mathrm{~K}$ & $a$ & $10^{4} \mathrm{~K}$ & $a$ & $10^{4} \mathrm{~K}$ \\
\hline 13700 & 33300 & 0.840 & 0.490 & 0.600 & 3.94 & - & - & - & - \\
\hline 46400 & 93300 & 0.700 & 1.72 & 0.551 & 7.84 & 0.681 & 1.40 & - & - \\
\hline 119200 & 490200 & 0.600 & 7.84 & - & - & 0.571 & 5.13 & 0.840 & 0.200 \\
\hline
\end{tabular}

a $M_{v}$, calculated by MHS equation in ref 11 .

b At $25^{\circ} \mathrm{C}$.

c At $38^{\circ} \mathrm{C}$.

creases with increasing $M .^{2,16}$ However, as shown in Table IV, the present value of $a$ decreases and the value of $K$ increases with increasing $M_{n}, M_{w}$, and $M_{v}$. That is, the present MHS constants obtained from one sample are not consistent with the Flory theory ${ }^{2}$ and the previous experimental results. ${ }^{16}$

In the past, MHS constants were obtained from $[\eta] M_{n} / K_{\mathrm{s}}$ and $[\eta] M_{w} / K_{\mathrm{s}} \cdot{ }^{3-6}$ Here, using the better calibration curve at $38^{\circ} \mathrm{C}$, MHS constants were also obtained from eq 19 and 20 (Table IV). Therefore, we may state that we should be very careful to measure GPC under good conditions when eq 19 and 20 are used.

\section{Determination of $a$ and $K$ from Two Samples}

The values calculated as MHS constants are shown in Table V. Here, they were not obtained using eq $25\left(M_{n 1}, M_{n 2}\right)=(13700$, $46400)$ and $(46400,119200)$ and eq $26\left(M_{w 1}, M_{w 2}\right)=(33300,93300)$. Dobbin et al. ${ }^{7}$ stated that the determination by eq 24 was quite good. However, with decreasing [ $\eta]$ (accordingly $M$ ), the present value of $a$ increases from 0.818 to 0.865 and the value of $K$ decreases from $0.269 \times 10^{-4}$ to $0.169 \times$ $10^{-4}$. As stated in Determination from One Sample, this is unreasonable. Thus, the use of eq 24 is not better. On the other hand, the MHS constants obtained by eq $26\left(M_{w}\right)$ and 27 $\left(M_{v}\right)$ are reasonable, because $a$ increases and $K$ decreases with increasing $M$. It is recommended to determine the MHS constant by eq 26 and 27 on the use of two samples.
Table $V$. The values of $a$ and $K$ obtained from two samples at $25^{\circ} \mathrm{C}$

\begin{tabular}{|c|c|c|c|}
\hline$M_{n 1}$ & $M_{n 2}$ & $a$ & $10^{4} \mathrm{~K}$ \\
\hline 13700 & 46400 & - & - \\
\hline 13700 & 119200 & 0.756 & 1.11 \\
\hline 46400 & 119200 & - & - \\
\hline $\begin{array}{c}M_{w 1} \\
33300\end{array}$ & $\begin{array}{l}M_{w 2} \\
93300\end{array}$ & - & - \\
\hline 33300 & 490200 & 0.564 & 6.10 \\
\hline 93300 & 490200 & 0.626 & 2.62 \\
\hline$[\eta]_{1}$ & {$[\eta]_{2}$} & & \\
\hline 0.160 & 0.320 & 0.865 & 0.169 \\
\hline 0.160 & 1.030 & 0.833 & 0.236 \\
\hline 0.320 & 1.030 & 0.818 & 0.290 \\
\hline$M_{v 1}$ & $M_{v 2}\left(a_{\mathrm{v}}, 10^{4} K_{\mathrm{v}}, \mathrm{ref}\right)^{\mathrm{a}}$ & & \\
\hline 40200 & $99000(0.70,0.75,11)$ & 0.660 & 1.40 \\
\hline 40200 & 447000 & 0.692 & 0.991 \\
\hline 99000 & 447000 & 0.709 & 0.790 \\
\hline 39800 & $96800(0.71,0.676,12)$ & 0.684 & 1.11 \\
\hline 39800 & 428000 & 0.716 & 0.786 \\
\hline 96800 & 428000 & 0.734 & 0.619 \\
\hline 41700 & $99100(0.73,0.53,13)$ & 0.729 & 0.636 \\
\hline 41700 & 421000 & 0.763 & 0.439 \\
\hline 99100 & 421000 & 0.781 & 0.343 \\
\hline 32600 & $81400(0.69,0.96,14)$ & 0.635 & 2.57 \\
\hline 32600 & 375000 & 0.667 & 1.80 \\
\hline 81400 & 375000 & 0.687 & 1.41 \\
\hline
\end{tabular}

a $\left(a_{\mathrm{v}}, K_{\mathrm{v}}\right)$, at $25^{\circ} \mathrm{C}$ in acetone.

Determination of $a$ and $K$ by the Method of Least Squares

The values obtained for MHS constants at 25 and $38^{\circ} \mathrm{C}$ are shown in Table VI. All eq 29-32 at $38^{\circ} \mathrm{C}$ yielded the MHS constants, but eq $29\left(M_{n}\right)$ and $32([\eta])$ at $25^{\circ} \mathrm{C}$ did not yield. This dif- 
Table VI. The values of $a$ and $K$ obtained from five samples

\begin{tabular}{|c|c|c|c|c|}
\hline \multirow{2}{*}{ Method } & \multicolumn{2}{|c|}{$25^{\circ} \mathrm{C}$} & \multicolumn{2}{|c|}{$38^{\circ} \mathrm{C}$} \\
\hline & $a$ & $10^{4} \mathrm{~K}$ & $a$ & $10^{4} K$ \\
\hline$M_{n}$ & - & - & 0.555 & 6.89 \\
\hline$M_{w}$ & 0.724 & 1.29 & 0.641 & 2.89 \\
\hline$[\eta]$ & - & - & 0.753 & 0.559 \\
\hline $\begin{array}{c}M_{v} \\
\left(a_{v}, 10^{4} K_{v}, \text { ref }\right)^{\mathrm{a}}\end{array}$ & & & & \\
\hline$(0.70,0.75,11)$ & 0.653 & 2.50 & 0.688 & 1.33 \\
\hline$(0.71,0.676,12)$ & 0.676 & 2.00 & 0.713 & 1.03 \\
\hline$(0.73,0.53,13)$ & 0.725 & 1.09 & 0.767 & 0.532 \\
\hline$(0.69,0.96,14)$ & 0.631 & 4.47 & 0.663 & 2.46 \\
\hline
\end{tabular}

a $\left(a_{\mathrm{v}}, K_{\mathrm{v}}\right)$, at $25^{\circ} \mathrm{C}$ in acetone.

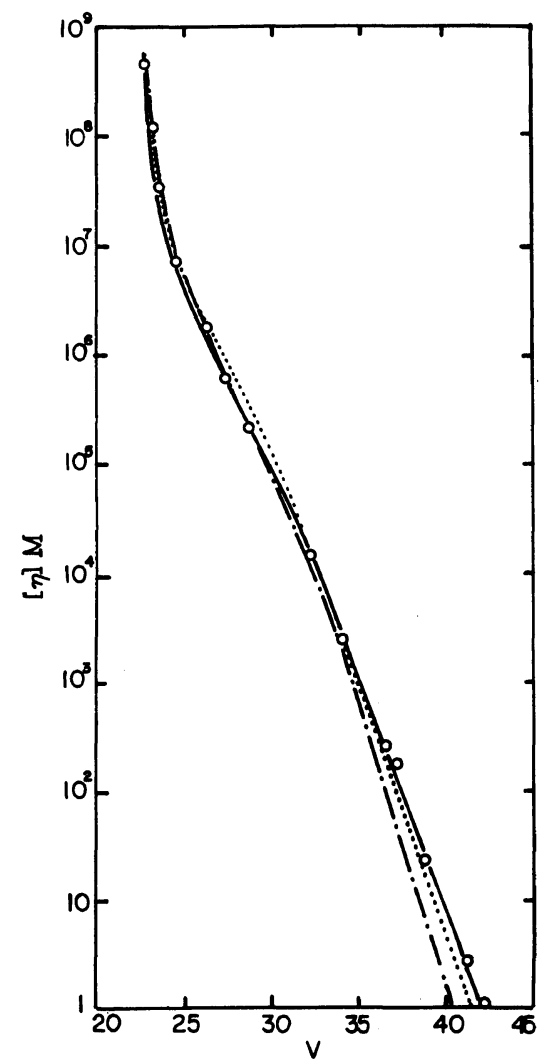

Figure 2. Relationships between $[\eta] M$ and $v$ at $38^{\circ} \mathrm{C}$ for polystyrene (O) and MMA by $M_{n}(-)$; by $M_{w}$ (----); by $[\eta](---)$.

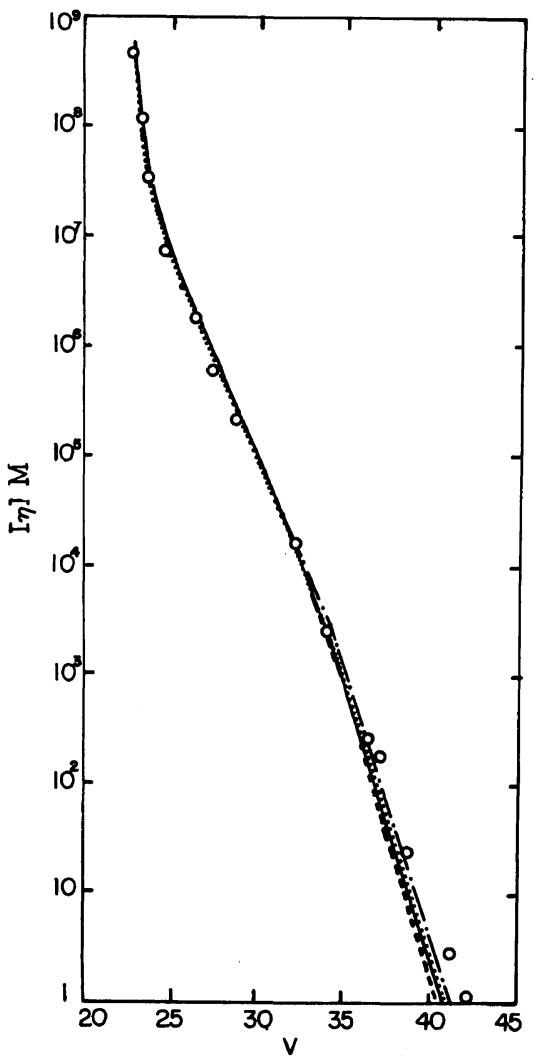

Figure 3. Relationships between $[\eta] M$ and $v$ at $38^{\circ} \mathrm{C}$ for polystyrene $(O)$ and MMA by $\left(\mathrm{a}, 10^{4} \mathrm{~K}\right)=(0.688$, $1.33)(----)$; $(0.713,1.03)(-) ;(0.767,0.532)(----)$; $(0.663,2.46)(-\cdot-)$.

ference may be from the fact that the calibration curve at $38^{\circ} \mathrm{C}$ is better than that at $25^{\circ} \mathrm{C}$, as stated previously. It is resulted that the MHS constants $\left(a_{v}, K_{v}\right)$ obtained previously ${ }^{11-14}$ can be transfered to new MHS constants $(a, K)$ by GPC. This transability is the same as the determination from two samples. The reason why these results are yielded is discussed in the following. To calculate exact $M_{n}$, the reading weight as $w_{i}$ at lower $M$ or larger $v$ must be precise. Unfortunately, it is more difficult at lower $M$, because $w_{i}$ is lower. Further, to calculate exact $M_{w}$, the reading $w_{i}$ at higher $M$ or smaller $v$ must be precise. However, it is also more difficult at higher $M$, because $w_{i}$ is also lower. Accordingly, the determinations by both 
$M_{n}$ and $M_{w}$ are not always good. On the other hand; to calculate exact $M_{v}$, it is not necessary to read so precisely $w_{i}$ at lower or higher $M$, but near median $M$ or $v$. In the median, the precise reading $w_{i}$ is easy, because we can read $w_{i}$ near the peak on the chromatogram. Thus, the exact $M_{v}$ can be calculated by GPC and the MHS constants $\left(a_{v}, K_{v}\right)$ can be transferred to the reasonable MHS constants $(a, K)$.

To examine the MHS constants obtained here on the basis of eq 1 , three curves of relationships between $[\eta] M$ and $v$ are made and shown in Figure 2, using the MHS constants obtained at $38^{\circ} \mathrm{C}$ from $M_{n}, M_{w}$, and [ $\left.\eta\right]$ and those in ref 10 as used in EXPERIMENTAL. The curve obtained from $M_{n}$ is the best to the plot for universal calibration made from the standard polystyrene when $v$ is larger. The curve obtained from $M_{w}$ is also a very good fit to the universal plot, except that it slightly deviates when $27<v<31$ and $v>37$. The curve obtained from $[\eta]$ to the universal plot when $v$ is smaller. Four curves made from $M_{v}$ are shown in Figure 3. Those fit the universal plot except when $v>36$. Thus, it may be proved that almost all the MHS constants $\left(a_{v}, K_{v}\right)$ are transferred to the respective good MHS constants $(a, K)$ on the basis of eq 1 . However, when $v$ is small except using $M_{n}$, the curves deviate from the universal. Experimentally and theoretically, a decreases with decreasing $M$ and approches $1 / 2$. $^{2,16}$ Then, use of the MHS constants in eq 33 and 34 are unreasonable when $v$ is so small that $M<3000 .^{15}$ To obtain such a curve as fit the universal curve, the present methods shown in THEORY and Table I are not better. Thus, the deviation from the universal plot when $M<3000$ may be resonable. In the near future, we will try to make the curve which is a fit to the universal curve when $M$ is small.

\section{NOMENCLATURE}

$\Phi=$ Flory's universal constant
$K_{\mathrm{s}}, a_{\mathrm{s}}=$ MHS constants for a standard polymer

$K, a=$ MHS constants for a polymer

$K_{\mathrm{v}}, a_{\mathrm{v}}=$ MHS constants to calculate the viscosityaverage molecular weight

$[\eta]_{\mathrm{s}} \quad=$ intrinsic viscosity for a standard polymer

$[\eta] \quad=$ intrinsic viscosity for a polymer

$M_{\mathrm{s}} \quad=$ molecular weight for a standard polymer with narrow molecular weight distribution

$M \quad=$ molecular weight for a polymer with narrow molecular weight distribution

$N_{i} \quad=$ number of $i$-th species in a polymer

$M_{\text {si }} \quad=$ molecular weight of $i$-th species in a standard polymer

$M_{i} \quad=$ molecular weight of $i$-th species in a polymer

$M_{n}=$ number-average molecular weight

$M_{w} \quad=$ weight-average molecular weight

$M_{v} \quad=$ viscosity-average molecular weight

$w_{i} \quad=$ weight fraction of $i$-th species in a polymer

$v \quad=$ elution volume or count number

$m \quad=$ number of samples

\section{REFERENCES}

1. G. Grubisic, P. Rempp, and H. Benoit, J. Polym. Sci., B, 5, 753 (1967).

2. P. J. Flory, "Principles of Polymer Chemistry," Cornell University Press, Ithaca, New York, 1953.

3. K. Weise and E. Cohn-Gensberg, J. Polym. Sci., Polym. Lett., 7, 379 (1969).

4. G. Braun, J. Appl. Polym. Sci., 15, 2321 (1971).

5. H. K. Mahabadi and K. F. O'Driscoll, J. Appl. Polym. Sci., 21, 1283 (1977).

6. K. Ito, Polym. J., 16, 139 (1984).

7. C. J. B. Dobbin, A. Rudin, and M. F. Tchir, J. Appl. Polym. Sci., 25, 2985 (1980).

8. S. Mori, Anal. Chem., 55, 2414 (1983).

9. H. Margenau and G. M. Murphy, "The Mathematics of Physics and Chemistry," D. Van Nostrand, New Haven, Conn., 1943.

10. T. Proder, J. C. Woodbrey, and J. H. Clark, ACS Symposium on GPC, HCS, Houston, Texas, Feb. 1970.

11. G. V. Schulz, H.-J. Cantow, and G. Meyerhoff, J. Polym. Sci., 10, 79 (1953).

12. G. V. Schulz and G. Meyerhoff, Z. Elektrochem., 56, 904 (1952).

13. H.-J. Cantow and G. V. Schulz, Physik. Chem., 1, 365 (1954); ibid., 2, 117 (1954).

14. S. N. Chinai, J. D. Matlack, A. L. Resnik, and R. J. Samules, J. Polym. Sci., 17, 391 (1955).

15. T. Proder and E. M. Rosen, Sep. Sci., 5, 437 (1970).

16. J. Brandrup and E. H. Immergut, "Polymer Handbook," John Wiley \& Sons, New York, N. Y., 1974. 